\title{
Cervical spine overflexion in a halo orthosis contributes to complete upper airway obstruction during awake bronchoscopic intubation: a case report
}

\section{L'hyperflexion de la colonne cervicale dans une orthèse de Halo contribue à l'obstruction totale des voies aériennes hautes au cours d'une intubation éveillée par bronchoscopie: étude de cas}

\author{
Alexander N. J. White, MD • David T. Wong, MD • \\ Christina L. Goldstein, MD $\cdot$ Jean Wong, MD \\ Received: 4 July 2014/Accepted: 24 November 2014/Published online: 3 December 2014 \\ (C) Canadian Anesthesiologists' Society 2014
}

\begin{abstract}
Purpose We present a case of upper airway obstruction in a patient with an unstable cervical spine fracture in a halo orthosis. We also describe the mechanism by which the obstruction occurred and identify features that predispose patients in a halo orthosis to upper airway obstruction.

Case An 81-yr-old female presenting to hospital with an unstable cervical spine fracture was scheduled for spinal fusion. She was fitted with a halo traction device in a flexed position, and an awake tracheal intubation was planned. The patient's airway was topicalized and $1 \mathrm{mg}$ of midazolam was administered. Her oxygen saturation dropped, and mask ventilation was difficult and insufficient. She then became unresponsive and pulseless. Emergency release of the halo orthosis device was carried out and her neck was held in a neutral position. Mask ventilation was successfully performed and oxygenation improved. The patient's trachea was intubated via video
\end{abstract}

Author contributions Alexander N.J. White and Jean Wong were responsible for the concept of the article and for writing the manuscript. David T. Wong and Christina L. Goldstein contributed to writing the manuscript

A. N. J. White, MD - D. T. Wong, MD

C. L. Goldstein, MD · J. Wong, MD

Department of Anesthesia and Toronto Western Hospital Spine

Program, Toronto Western Hospital, University Health Network,

University of Toronto, Toronto, ON, Canada

J. Wong, MD ( $₫)$.

Department of Anesthesia, 2McL-405, Toronto Western

Hospital, University Health Network, 399, Bathurst Street,

Toronto, ON M5T 2S8, Canada

e-mail: jean.wong@uhn.ca laryngoscopy, and she was resuscitated and taken to the intensive care unit. The degree of cervical spine flexion resulting from the halo fixation was examined in subsequent radiographs, as defined by the occiput to $C 2$ $(\mathrm{O}-\mathrm{C} 2)$ angle, and the oropharyngeal cross-sectional area was measured. Spine flexion from halo fixation in concert with the topical treatment and sedation predisposed the patient to acute airway obstruction.

Conclusion In this case, external cervical spine fixation in flexion resulted in a change to the $\mathrm{O}-\mathrm{C} 2$ angle, which reduced the oropharyngeal area and predisposed to upper airway obstruction. This highlights the need for anesthesiologists to evaluate the degree of cervical spine flexion in patients with halo devices and to have the surgical team present during airway management in the event of acute airway obstruction.

\section{Résumé}

Objectif Nous présentons un cas d'obstruction des voies aériennes hautes chez une patiente dans une orthèse de Halo pour fracture instable de la colonne cervicale. Nous décrivons également le mécanisme ayant conduit à l'obstruction et identifions les caractéristiques qui prédisposent les patients dans une orthèse de Halo à l'obstruction des voies aériennes hautes.

Cas Une femme âgée de 81 ans avec fracture instable de la colonne cervicale s'est présentée à l'hôpital pour y subir une arthrodèse vertébrale programmée. Elle a été équipée d'un dispositif de traction Halo en position fléchie et une intubation trachéale éveillée a été planifiée. Les voies aériennes de la patiente ont été anesthésiées localement et elle a reçu $1 \mathrm{mg}$ de midazolam. Sa saturation en oxygène 
s'est alors effondrée, la ventilation au masque s'est avérée difficile et insuffisante. Elle est devenue inconsciente et son pouls a disparu. Libérée d'urgence du dispositif d'orthèse Halo, son cou étant maintenu en position neutre, une ventilation au masque a pu être menée avec succès et l'oxygénation s'est améliorée. La trachée de la patiente a été intubée sous vidéolaryngoscopie et elle a été conduite en unité de soins intensifs après avoir été réanimée. Le degré de flexion de la colonne cervicale (défini par l'angle occiput sur C2 [O-C2]) résultant de la fixation du Halo a été analysé sur des radiographies ultérieures et l'aire de coupe transversale oropharyngée a été mesurée. La flexion de la colonne due à la fixation dans le Halo, associée au traitement topique et à la sédation ont prédisposé à l'obstruction aiguë des voies aériennes de la patiente.

Conclusion Dans ce cas, une fixation cervicale externe en flexion a entraîné une modification de l'angle O-C2 qui a réduit la surface oropharyngée et a prédisposé à l'obstruction de la voie aérienne haute. Cela souligne le besoin, pour les anesthésiologistes, d'évaluer le degré de flexion de la colonne cervicale chez les patients porteurs de dispositifs de Halo et de ne gérer la voie aérienne que lorsque l'équipe chirurgicale est présente, dans l'éventualité d'une obstruction des voies aériennes hautes.

Halo immobilization of unstable cervical spine injuries necessitates special consideration of the airway. Awake flexible bronchoscopic intubation is considered one of the safest ways to secure the airway in this patient population. External fixation of the patient's neck in a flexed position makes airway manipulation difficult. It reduces the mouth opening and prevents manipulation of the head position. Numerous case reports of fixed flexion of the cervical spine have described postoperative airway obstruction as a result of overflexion of the cervical spine. ${ }^{1-3}$ Although the application of halo immobilization in cervical spine fractures has been shown to result in acute airway compromise, ${ }^{4}$ these patients are usually immediately symptomatic. In this case report, we describe a patient who did not experience respiratory distress immediately following placement of a halo orthosis; rather, she developed almost complete airway obstruction during topicalization of her airway in preparation for awake intubation. The patient provided written informed consent for the preparation and submission of this case report.

\section{Case report}

An 81-yr-old female (weight $50 \mathrm{~kg}$, height $152 \mathrm{~cm}$, body mass index 21.6) presented to hospital after a mechanical fall. Radiographs and a computed tomography (CT) scan showed a coronal fracture of the $\mathrm{C} 2$ vertebral body and a sagittal fracture of the $\mathrm{C} 3$ vertebra. There were no other injuries associated with the fall. She was previously in relatively good health with a history of high cholesterol and osteoporosis. She did not endorse symptoms of obstructive sleep apnea. A trial of non-operative management in an Aspen ${ }^{\circledR}$ collar was initiated; however, rotational instability at the C1-2 articulation occurred three days later. The patient was subsequently placed in a halo ring with traction, followed by conversion to a halo vest, and she was scheduled to undergo an occiput to $\mathrm{C} 4$ posterior instrumented fusion two days later.

The evening before surgery, her preoperative evaluation revealed no respiratory distress and normal vital signs and oxygen saturation. She had no neurologic deficits, and she was alert, oriented, and ambulatory with assistance. Her neck was fixed in a halo orthosis. An airway examination revealed a Mallampati score of 3 and a reduced thyromental distance. She had no dental abnormalities. Her mouth opening and mandibular protrusion were both reduced.

In the operating room, the patient received glycopyrrolate $0.2 \mathrm{mg} i v$ and midazolam $1 \mathrm{mg} i v$ in preparation for an awake bronchoscopic intubation. Five minutes later, she was placed on oxygen via nasal prongs and received approximately $100 \mathrm{mg}$ of lidocaine topically via two pledgets inserted orally into the piriform fossa bilaterally for one to two minutes in order to block the superior laryngeal nerve. This was followed by $200 \mathrm{mg}$ of lidocaine administered via an atomizer. The topical application took place over ten minutes, and almost immediately after the topical treatment was completed, before insertion of the flexible bronchoscope, the patient experienced tachycardia and became unresponsive and hypoxic. Bag-mask ventilation was attempted with an oropharyngeal airway; however, the patient desaturated to an $\mathrm{SpO}_{2}$ of $80 \%$ which was unresponsive to mask ventilation. Despite a jaw thrust maneuver and insertion of an oropharyngeal airway, ventilation could not be achieved. Over the next minute, the quality of the pulse oximeter waveform diminished to very poor and the patient became cyanotic. An ear pulse oximeter was then applied, but the quality of the waveform did not improve. The patient showed signs of bradycardia with a heart rate of 52 beats. $\min ^{-1}$, and she was hypotensive with a systolic blood pressure of $75 \mathrm{mmHg}$. Oral bronchoscopic intubation was briefly attempted; however, neither the epiglottis nor the vocal cords were visualized. The patient became pulseless and cardiopulmonary resuscitation (CPR) was initiated. During CPR, the neurosurgical team released the halo vest, and manual inline stabilization was provided with the patient's neck in a neutral position. Her oxygen saturation 
improved to $98 \%$ upon release of the halo immobilization. The patient's trachea was intubated successfully using a Karl Storz C-Mac ${ }^{\circledR}$ dBlade $^{\mathrm{TM}}$ video laryngoscope. A pulse was regained after approximately $30 \mathrm{sec}$ of CPR; her oxygen saturation improved to $100 \%$, and she was transferred to the intensive care unit. Subsequent evaluations did not reveal any neurologic deficits. Postoperatively, lateral radiographs taken before and after fixation in the halo orthosis (Figs. 1a and 1b) were examined. The change in occipital angle to $\mathrm{C} 2$ (O-C2) before and after fixation showed that the patient's cervical spine was fixed in overflexion, which likely contributed to the development of airway obstruction. The patient's trachea was left intubated, and her surgery was successfully completed ten days later. She was discharged back to her local hospital with no neurologic deficits and was eventually discharged home one month later.

\section{Discussion}

The above case depicts an acute upper airway obstruction in a patient with halo vest immobilization of an upper cervical fracture subluxation that was relieved with release of the halo vest.

A halo orthosis consists of a carbon fibre ring secured to the skull with pins. Rods attach the ring to a well-fitted plastic jacket worn over the shoulders. In upper cervical spine injuries, it is the most effective method of external immobilization of the cervical spine. ${ }^{5}$ Nevertheless, external fixation of the neck in a flexed position makes airway manipulation difficult. It reduces the mouth opening and prevents manipulation of the head position.

The degree of cervical spine flexion is described by Miyata et al. as the $\mathrm{O}-\mathrm{C} 2$ angle. ${ }^{6}$ This is measured as the angle between McGregor's line (a straight line connecting the posterior edge of the hard palate to the most inferior tip of the occipital curve) and the line formed by the inferior endplate of the $\mathrm{C} 2$ vertebral body. Miyata et al. compared changes in the O-C2 angle before and after occipitocervical fusion with an oropharyngeal cross-sectional area (measured from an axial view at the level of the tip of the epiglottis on a CT scan of the neck). They found that a change in the $\mathrm{O}-\mathrm{C} 2$ angle $>10^{\circ}$ is associated with narrowing of the oropharynx and postoperative dyspnea and dysphagia. ${ }^{6}$

The measurements of our patient's O-C2 angle before and after halo fixation were $26.5^{\circ}$ and $9.5^{\circ}$, respectively, for a reduction of $17^{\circ}$ following application of the halo orthosis (Figs. 1a and 1b). The measurements of her oropharyngeal cross-sectional area before and after halo fixation were $1.17 \mathrm{~cm}^{2}$ and $0.53 \mathrm{~cm}^{2}$, respectively, for a
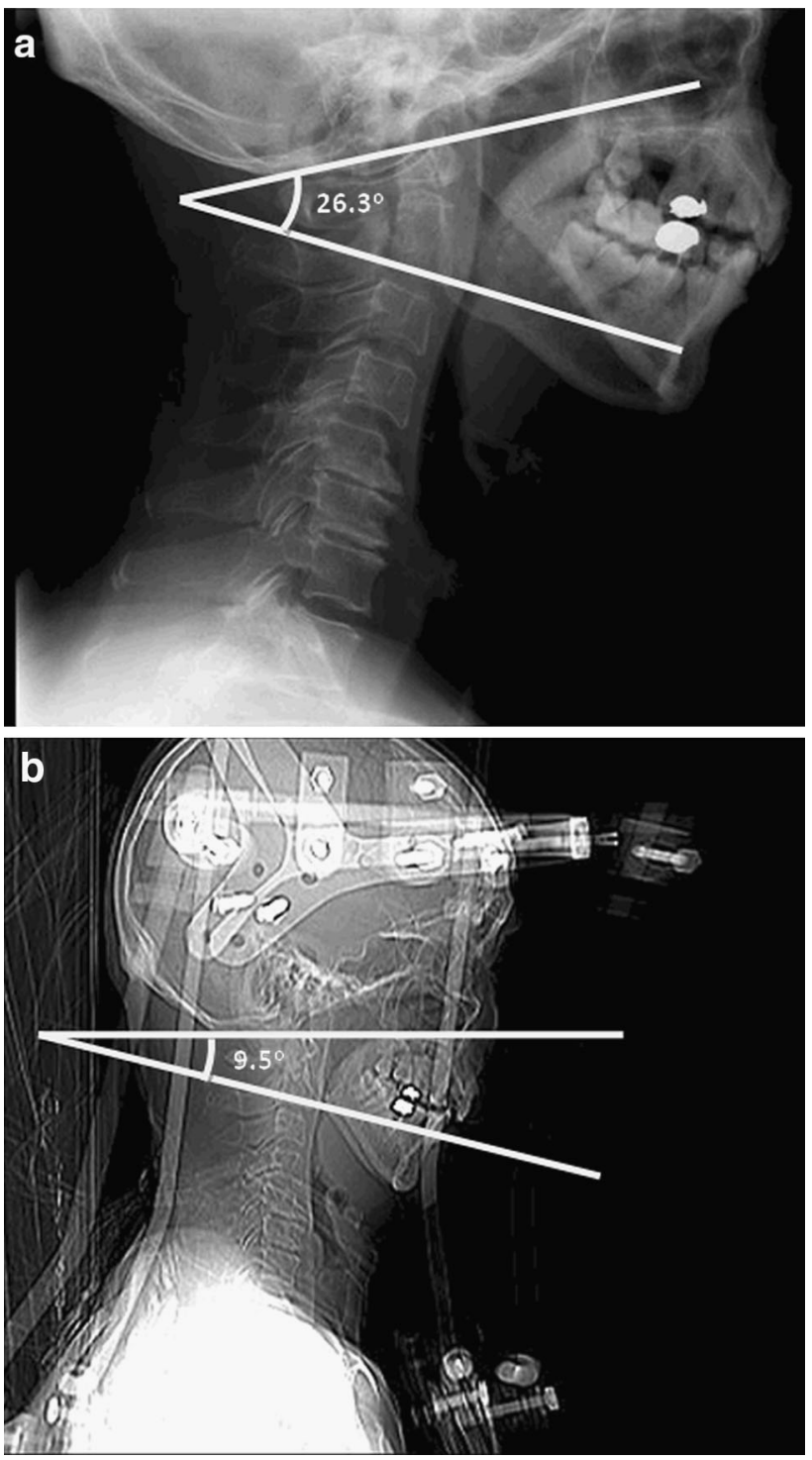

Figure 1 Lateral cervical spine radiographs (a) before and (b) after application of the halo fixation device. The $\mathrm{O}-\mathrm{C} 2$ angle measurements show a $17^{\circ}$ reduction in the $\mathrm{O}-\mathrm{C} 2$ angle

reduction of 55\% (Figs. 2a and 2b). Although there is no well-defined minimum oropharyngeal cross-sectional area required for airway patency, studies have shown that a smaller oropharyngeal cross-sectional area correlates with a greater degree of obstructive sleep apnea, (i.e., a mechanical obstruction). ${ }^{7,8}$ In one study, an oropharyngeal cross-sectional area of $\leq 0.5 \mathrm{~cm}^{2}$ was associated with severe sleep apnea. ${ }^{7}$

Overflexion of the cervical spine reduces the crosssectional area of the oropharynx, increasing susceptibility to airway obstruction. Sedation and topical treatment reduces the tone of the upper airway muscles. Numerous studies have shown that topical treatment of the airway can reduce airflow and result in transient obstruction of the 

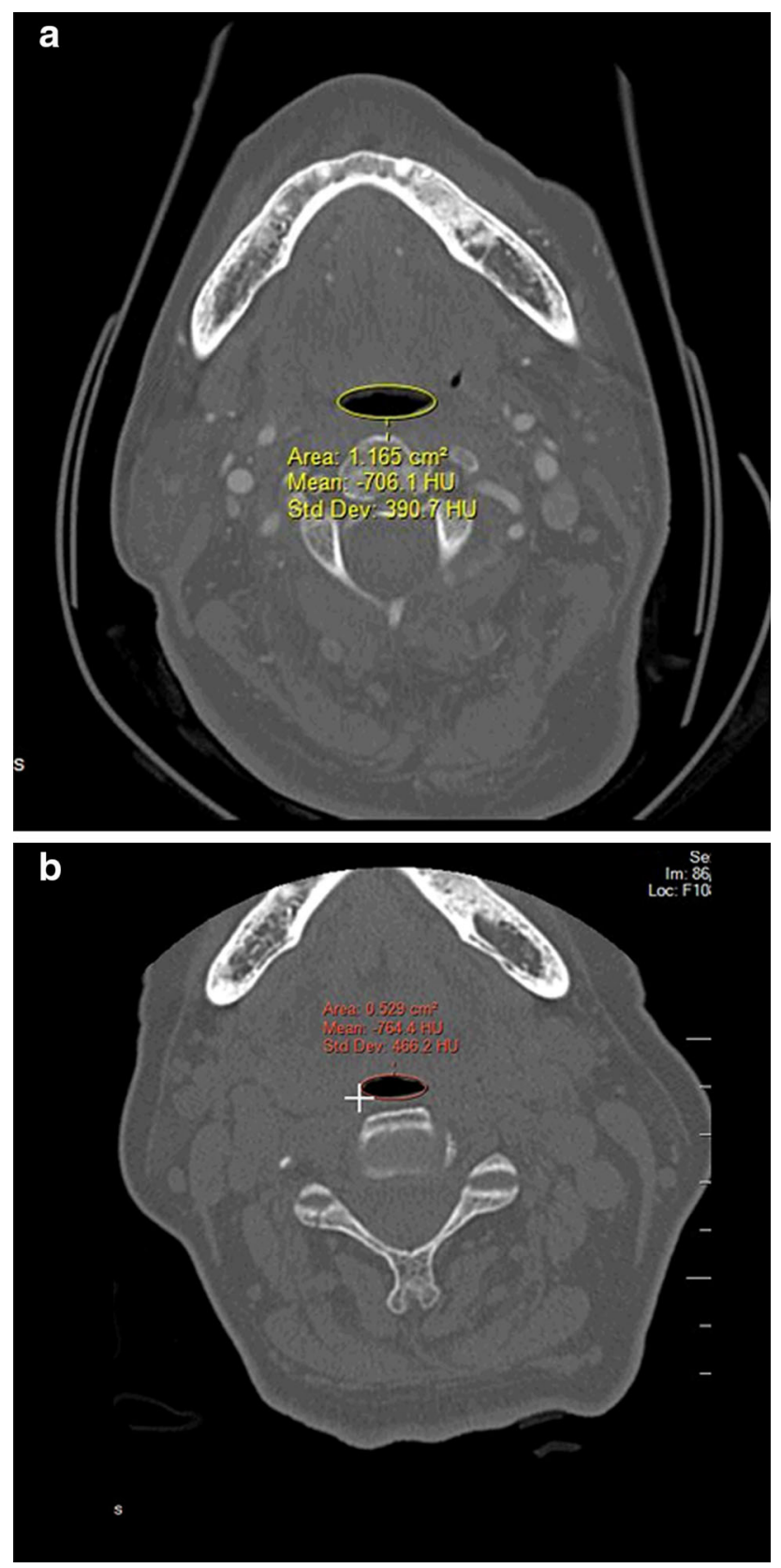

Figure 2 Axial computed tomography radiographs at the level of the tip of the epiglottis (a) before and (b) after application of halo fixation device. Measurements of the oropharyngeal cross-sectional area show a $55 \%$ reduction

glottis in otherwise healthy individuals. ${ }^{9-11}$ Shaw et al. describe a case of airway obstruction during topical treatment of the upper airway. ${ }^{12}$ Due to our patient's increased susceptibility to airway obstruction, the sedation and topical treatment she received probably caused complete obstruction. While some cervical spine flexion may be required to achieve acceptable fracture alignment, ensuring an adequate fixation angle when placing a halo fixation collar can help to avoid placing patients at risk for airway obstruction. As patients may be asymptomatic, it may not be realized that they are at risk of airway obstruction until they receive topical treatment and sedation. Preoperatively, anesthesiologists should review the radiographic images with the surgery team before proceeding with an awake bronchoscopic intubation. Extra caution should also be taken to evaluate the degree of flexion in patients with halo fixation, and sedating medication should be used judiciously, if at all. Although a supraglottic airway, such as a laryngeal mask airway device (LMAD) is often used as an emergency rescue device in a difficult airway scenario, we did not attempt to use a supraglottic airway in this situation. It is well known that LMAD insertion can be difficult in patients with fixed flexion of the cervical spine. ${ }^{13-15}$ This has been attributed to the relatively acute angle between the oral and pharyngeal axes. ${ }^{13}$ Nevertheless, it may be reasonable to attempt to insert a supraglottic airway to restore airway patency in an emergency before release of the halo. Furthermore, members of the surgical team should be present and available to assist with emergency release of halo traction - these patients have a large degree of cervical spine instability - and to assist with a surgical airway should the above measures fail to restore upper airway patency. Given the flexed neck position in a halo orthosis and unstable fracture, a surgical airway would have been technically difficult and not the first option unless the airway could not be secured non-invasively after the halo device was released.

Although our patient did not have operative fusion of the cervical vertebrae, halo fixation may produce a very similar result mechanically, that is, fixed overflexion of the cervical spine. This is a novel case report documenting complete airway obstruction secondary to halo immobilization during preparation for awake intubation, followed by improvement with release of the halo prior to surgery. In one case report, Hiller describes a situation in which overflexion from halo fixation caused desaturation, tachypnea, and a challenging airway. ${ }^{16}$ In another case report, McGuire et al. describe two patients in halo traction who had complete upper airway obstruction after receiving topical treatment and sedation for awake bronchoscopic intubation. ${ }^{17}$ It is possible that overflexion of the cervical spine went unrecognized in these cases and contributed to the development of airway obstruction.

This case illustrates the potential for airway obstruction due to fixed overflexion of the cervical spine in halo fixation before surgery. Minimal sedation and topical treatment of the airway worsened the airway obstruction, and recognition of this iatrogenic condition was critical, as releasing the halo fixation was essential for successful resuscitation of this patient. 
Funding sources Supported in part by the Department of Anesthesia, Toronto Western Hospital, University of Toronto, ON, Canada.

Conflicts of interest None declared.

\section{References}

1. Yoshida $M$, Neo M, Fujibayashi S, Nakamura T. Upper-airway obstruction after short posterior occipitocervical fusion in a flexed position. Spine (Phila Pa 1976) 2007; 32: E267-70.

2. Lee $Y H$, Hsieh $P F$, Huang $H H$, Chan $K C$. Upper airway obstruction after cervical spine fusion surgery: role of cervical fixation angle. Acta Anaesthesiol Taiwan 2008; 46: 134-7.

3. Tagawa T, Akeda K, Asanuma $Y$, et al. Upper airway obstruction associated with flexed cervical position after posterior occipitocervical fusion. J Anesth 2011; 25: 120-2.

4. Harrop JS, Vaccaro A, Przybylski GJ. Acute respiratory compromise associated with flexed cervical traction after C2 fractures. Spine (Phila Pa 1976) 2001; 26: E50-4.

5. Pieron AP, Welply WR. Halo traction. J Bone Joint Surg Br 1970; 52: $119-23$.

6. Miyata M, Neo M, Fujibayashi S, Ito H, Takemoto M, Nakamura T. O-C2 angle as a predictor of dyspnea and/or dysphagia after occipitocervical fusion. Spine (Phila Pa 1976) 2009; 34: 184-8.

7. Avrahami E, Englender M. Relation between CT axial crosssectional area of the oropharynx and obstructive sleep apnea syndrome in adults. Am J Neuroradiol 1995; 16: 135-40.
8. Yucel A, Unlu M, Haktanir A, Acar M, Fidan F. Evaluation of the upper airway cross-sectional area changes in different degrees of severity of obstructive sleep apnea syndrome: cephalometric and dynamic CT study. AJNR Am J Neuroradiol 2005; 26: 2624-9.

9. Kuna ST, Woodson GE. Sant'Ambrogio, G. Effect of laryngeal anesthesia on pulmonary function testing in normal subjects. Am Rev Respir Dis 1998; 137: 656-61.

10. Listro G, Stänescu DC, Veriter C, Rodenstein DO, D'Odemont $J P$. Upper airway anesthesia induces airflow limitation in awake humans. Am Rev Respir Dis 1992; 146: 581-5.

11. Beydon L, Lorino AM, Verra F, et al. Topical upper airway anaesthesia with lidocaine increases airway resistance by impairing glottic function. Intensive Care Med 1995; 21: 920-6.

12. Shaw IC, Welchew EA, Harrison BJ, Michael S. Complete airway obstruction during awake fibreoptic intubation. Anaesthesia 1997; 52: $582-5$.

13. Ishimura $H$, Minami $K$, Sata $T$, Shigematsu A, Kadoya $T$. Impossible insertion of the laryngeal mask airway and oropharyngeal axes. Anesthesiology 1995; 83: 867-9.

14. Kumar R, Prashast, Wadhwa A, Akhtar S. The upside-down intubating laryngeal mask airway: a technique for cases of fixed flexed neck deformity. Anesth Analg 2002; 95: 1454-8.

15. Law JA, Broemling N, Cooper RM, et al. The difficult airway with recommendations for management - Part 2 - The anticipated difficult airway. Can J Anesth 2013; 60: 1119-38.

16. McGuire $G$, el-Beheiry $H$. Complete upper airway obstruction during awake fibreoptic intubation in patients with unstable cervical spine fractures. Can J Anesth 1999; 46: 176-8.

17. Hiller $K N$. Excessive occipital-C1 flexion via halo vest immobilization: oropharyngeal space reduction leading to difficult airway establishment. Anesthesiology 2013; 118: 711. 